\title{
The influence of edge effects on crack propagation in snow stability tests
}

\author{
E. H. Bair ${ }^{1,2}$, R. Simenhois ${ }^{3}$, A. van Herwijnen ${ }^{4}$, and K. Birkeland ${ }^{5}$ \\ ${ }^{1}$ US Army Corps of Engineers Cold Regions Research and Engineering Laboratory, Hanover, NH, USA \\ ${ }^{2}$ Earth Research Institute, University of California, Santa Barbara, CA, USA \\ ${ }^{3}$ Southeast Alaska Avalanche Center, Juneau, AK, USA \\ ${ }^{4}$ WSL Institute for Snow and Avalanche Research SLF, Davos, Switzerland \\ ${ }^{5}$ USDA Forest Service National Avalanche Center, Bozeman, MT, USA
}

Correspondence to: E. Bair (nbair@eri.ucsb.edu)

Received: 24 October 2013 - Published in The Cryosphere Discuss.: 9 January 2014

Revised: 18 June 2014 - Accepted: 19 June 2014 - Published: 5 August 2014

\begin{abstract}
The Extended Column Test (ECT) and the Propagation Saw Test (PST) are two commonly used tests to assess the likelihood of crack propagation in a snowpack. Guidelines suggest beams with lengths of around $1 \mathrm{~m}$, yet little is known about how test length affects propagation. Thus, we performed 163 ECTs and PSTs $1.0-10.0 \mathrm{~m}$ long. On days with full crack propagation in $1.0-1.5 \mathrm{~m}$ tests, we then made videos of tests $2.0-10.0 \mathrm{~m}$ long. We inserted markers for particle tracking to measure collapse amplitude, propagation speed, and wavelength. We also used a finite element (FE) model to simulate the strain energy release rate at fixed crack lengths. We find that (1) the proportion of tests with full propagation decreased with test length; (2) collapse was greater at the ends of the beams than in the centers; (3) collapse amplitude was independent of beam length and did not reach a constant value; (4) collapse wavelengths in the longer tests were around $3 \mathrm{~m}$, two times greater than what is predicted by the anticrack model. We also confirmed the prediction that centered PSTs had double the critical length of edge PSTs. Based on our results, we conclude that cracks propagated more frequently in the shorter tests because of increased stress concentration from the far edge. The FE model suggests this edge effect occurs for PSTs of up to $2 \mathrm{~m}$ long or a crack to beam length ratio $\geq 0.20$. Our results suggest that ECT and PST length guidelines may need to be revisited.
\end{abstract}

\section{Introduction}

Snow stability tests are used to evaluate avalanche hazard. Based on SnowPilot pit data across the US over the last decade (Birkeland and Chabot, 2012), the three most popular tests are, in this order: (1) the Extended Column Test (ECT), (2) the Compression Test (CT), and (3) the Propagation Saw Test (PST). The CT is the oldest of the three and has been in use since the 1970s (Jamieson, 1999). Briefly, the CT involves isolating a column of $30 \times 30 \mathrm{~cm}$ that is deep enough to include the slab and the failure layer. The column is loaded by tapping a shovel placed on top of the snow with increasing force. The number of taps to failure as well as the quality and character of the failure are recorded (e.g., van Herwijnen and Jamieson, 2007). The ECT is similar to the CT except that the isolated beam is longer, typically $30 \mathrm{~cm}$ wide $\times 90 \mathrm{~cm}$ long. In the ECT, the most important observation is whether or not the crack propagates across the beam. The PST has similar dimensions to the ECT, but the beam is loaded by creating a progressively longer notch in the weak layer with the blunt end of a snow saw. The length of the critical notch, when the crack self-propagates, is recorded. For comprehensive guidelines for these tests, see Greene et al. (2010).

The CT has proven to be an effective test for crack initiation, but because of the small size of the column, it cannot be used to study crack propagation. Crack initiation refers to the stage of fracture where cracks are shorter than the critical length; that is, cracks do not self-propagate. If cracks reach a critical length, they self-propagate. We refer to this stage of fracture as propagation. A critical crack self-propagates 
without any external changes in the system, i.e., the crack propagates without additional load. The distinction between stages is important for avalanche hazard evaluation because initiation may only result in a local failure, e.g., cracking at the trigger, while propagation can result in the failure of a slope, i.e., an avalanche. Crack propagation is an open area of avalanche research, with a debate on whether cracks propagate in shear (McClung, 1979) or in mixed-mode collapse/shear (anticrack; Heierli et al., 2008) waves. Recently, two tests were developed to examine crack propagation: The ECT (Simenhois and Birkeland, 2006, 2009) and the PST (Sigrist and Schweizer, 2007; Gauthier and Jamieson, 2008).

Stability tests will always suffer from edge effects because they use isolated beams that are orders of magnitude smaller than avalanche slabs. For instance, the longest crack propagation length recorded in previously published studies has been about $3 \mathrm{~m}$ (van Herwijnen and Jamieson, 2005; Gauthier and Jamieson, 2008; van Herwijnen et al., 2010; van Herwijnen and Birkeland, 2014). Also, cracks likely propagate radially from a trigger in an avalanche, while in PSTs and ECTs, cracks are forced to travel in a straight path. Attempts have been made to reduce edge effects by, for example, not cutting the far end of the beam in PSTs (McClung, 2009). An "uncut" back end showed significantly shorter crack propagation lengths (Ross and Jamieson, 2012), suggesting that beam isolation aids propagation. In contrast, the critical cut length $r_{\mathrm{c}}$, the cut length needed to initiate self-propagation, did not change with increasing beam length (Gauthier and Jamieson, 2008) or uncut/cut back ends (Ross and Jamieson, 2012). Because the beam ends affect crack propagation, centered propagation tests (centered ECTs - CECTs and centered PSTs - CPSTs; Heierli, 2008; Heierli et al., 2011) have been proposed. In a centered ECT, the shovel is placed at the center, rather than the edge of the beam, and then tapped/hit in the same manner. In a centered PST, the saw is placed at the center, rather than the edge of the beam, then drawn either uphill or downhill. The location where the saw was inserted must be marked prior to propagation to measure $r_{\mathrm{c}}$.

Whether or not these centered tests reduce edge effects has not been tested. The theoretical prediction from the anticrack model is that the critical cut length doubles for a CPST compared to a PST (Heierli, 2008).

The standard beam length for ECTs and PSTs is about $1 \mathrm{~m}$. Technically, ECT guidelines suggest $0.9 \mathrm{~m}$ (Simenhois and Birkeland, 2009), while PST guidelines (Gauthier and Jamieson, 2008) suggest the greater of $1.0 \mathrm{~m}$ or the height of the slab. These length guidelines have not been rigorously evaluated in terms of how the stress field is affected by test length.

The anticrack model assumes a steady state for the collapse wave (i.e., constant collapse amplitude, wave speed, and wavelength), but experimental results have not shown a steady state. One reason suggested is that tests of $3 \mathrm{~m}$ or less are not long enough to allow a steady state collapse wave to develop (van Herwijnen et al., 2010). Alternatively,
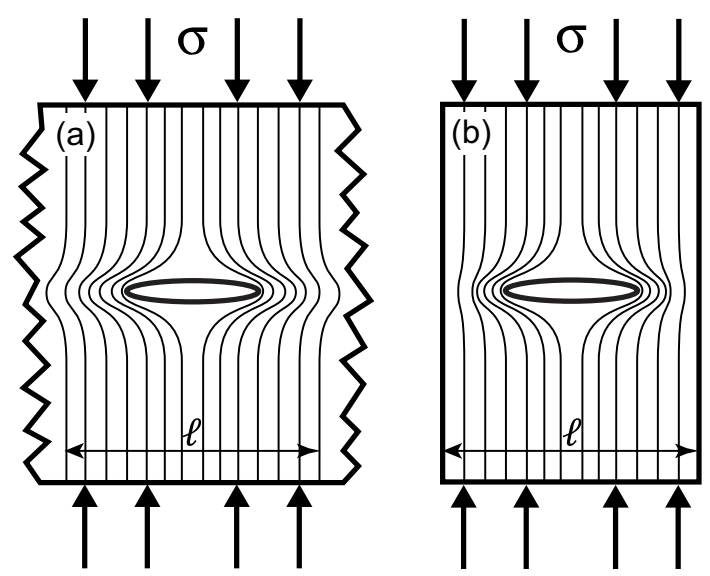

Figure 1. Stress concentration from edges. An infinite plate subject to a remote compressive stress (a) compared to a finite plate (b) subjected to the same stress. The tighter spacing between the lines of force represents higher local stress. The oval in the center is the crack. Shown for scale is length $\ell$. Adapted from Anderson (2005).

a steady state collapse wave may never develop. Longer tests are needed to verify the steady state assumption.

For typical slabs and weak layers, the anticrack model predicts a wavelength of $0.3-3.0 \mathrm{~m}$, depending primarily on the elastic modulus of the slab, the collapse wave speed, and the collapse amplitude. The only published experiment shows a wavelength estimate of $1.6 \mathrm{~m}$ (Heierli, 2008). The paucity of wavelength estimates can be explained by the fact that collapse wavelengths may be equal in length to the longest tests published, making it difficult to accurately estimate the wavelength.

\section{Background and field methods}

\subsection{Edge effects in propagation tests}

In field and laboratory fracture tests, edge effects are always present. These edge effects can cause the strain energy release rate $G$ to depend on sample size. Because free edges cannot transmit stress, they act as stress concentrators (e.g., Fig. 1). The PST and ECT suffer from two main edge effects. One edge effect is due to the sides (parallel faces, with the outer face labeled "slab" in Fig. 2). The crack nucleus in both tests can be considered a through crack, meaning that the crack extends from one side to the other. This obviously does not model a crack nucleus in an avalanche, which is an embedded crack; that is, a crack nucleus far from any edges. A through-crack configuration significantly increases stress at the crack tip compared to an embedded crack (Newman and Raju, 1981). It may be possible to use a beam that is significantly wider than a shovel in an ECT to reduce this edge effect, but we are not aware of any studies which have done this. 


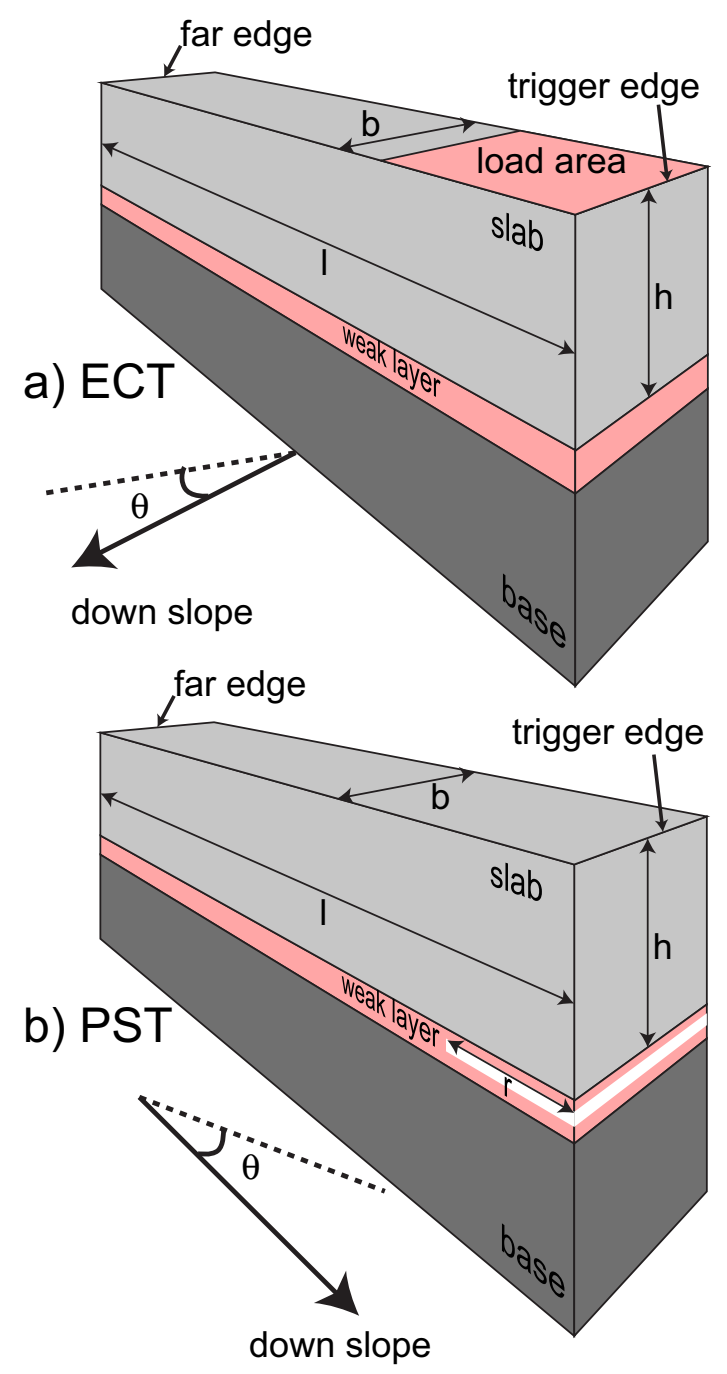

Figure 2. ECT and PST geometry. Shown are the slab width $b$, slab height $h$, length $l$, slope angle $\theta$, crack length $r$, and the far/trigger edges of the slab.

A second edge effect is caused by the front and back of the beam ("far edge" and "trigger edge" in Fig. 2). While centered tests should reduce this edge effect, CECTs and CPSTs are not widely used because they require about twice as much snow to be excavated for the same crack propagation length as standard tests. Further, we suggest that the trigger edge causes less bias in test results than the far edge. Whether or not a crack reaches the far edge is vital to determining propagation likelihood. Conversely, collapse at the trigger end is common and offers little insight into propagation likelihood. Thus we include some CPSTs results, but focus on the far edge effect in standard tests.

\section{$2.2 \quad$ Field tests}

We performed 163 tests over two winters in California, Utah, and Montana, USA. We began with standard $1.0-1.5 \mathrm{~m}$ tests.
If those tests had full crack propagation, we performed progressively longer tests, sometimes up to $10 \mathrm{~m}$. For the CPSTs, all tests had a beam length $l$ of $1.7 \mathrm{~m}$. We also took standard snow profile measurements at each site, including layers, densities, grain classification, etc. (Fierz et al., 2009).

We categorized tests results by three types of crack propagation. (1) Full propagation - the crack propagated to the far edge of the beam (Fig. 2). For the PST, we also restricted $r_{\mathrm{c}} \leq 50 \mathrm{~cm}$ to compare results with ECTs. PSTs with $r_{\mathrm{c}}>50 \mathrm{~cm}$ likely create a considerably larger crack nucleus than ECTs, which mostly crack the area of the beam under the shovel (van Herwijnen and Birkeland, 2014). For comparison, the shovels used for ECTs were square shaped and $25-30 \mathrm{~cm}$ in width $b$. (2) Partial propagation - the crack traveled $>r_{\mathrm{c}}$ from the far edge of the saw (edge closest to far edge of the beam) in a PST and $>b$ from the far edge of the shovel in an ECT, but arrested before reaching the far edge of the beam. (3) No propagation - the crack traveled $<r_{\mathrm{c}}$ from the far edge of the saw in a PST and $<b$ from the far edge of the shovel in an ECT.

\subsection{Particle tracking}

We filmed tests with a Casio EX-ZR100. The shorter (1$2 \mathrm{~m})$ tests were filmed at lower resolution and higher speed, $432 \times 320$ pixels and 240 frames per second (fps). Most of the longer tests were filmed at higher resolution and lower speed, $1920 \times 1080$ pixels and $30 \mathrm{fps}$. We found this tworesolution approach gave us the most accurate displacement measurements for tests spanning an order of magnitude in length.

Black markers, $25 \mathrm{~mm}$ in diameter, were placed into the side of the beam and tracked to measure displacement, wave speed, and collapse amplitude. For specifics on the particle tracking methodology, see previous work on particle tracking with stability tests (van Herwijnen and Jamieson, 2005; van Herwijnen and Heierli, 2009; van Herwijnen et al., 2010; Bair et al., 2012; van Herwijnen and Birkeland, 2014). Similar to another study (van Herwijnen and Birkeland, 2014), we found it was often not possible to track particles near the shovel during ECTs because of snow compaction under the shovel.

Wavelength was estimated visually by plotting the collapse wave at different times during failure, with accuracy equal to the marker spacing, typically $0.5 \mathrm{~m}$. There are three phases of vertical displacement during failure: (i) bending, (ii) rapid collapse, and (iii) bed surface erosion. To measure the wavelength, we attempted to isolate (ii); including (i) and (iii) would lead to wave lengths that are too long.

Processing was done in MATLAB (MathWorks, 2013) using open source particle tracking functions (Crocker and Grier, 1996). Images were contrast enhanced and displacements were smoothed using a smoothing function (MATLAB function "robust loess") with a window length of 9. Uncertainty was computed using the standard deviation of each 


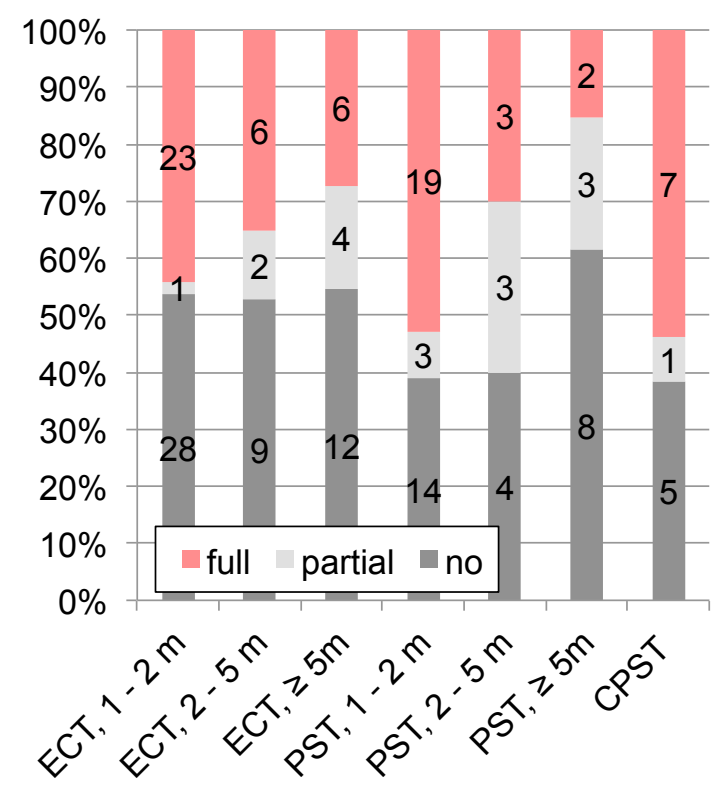

Figure 3. Propagation summary chart. Stacked columns are percentages of tests that had no, partial, or full crack propagation. Each stacked column refers to a type of test (see Sect. 1) and beam length. Numbers inside stacked columns are counts of each propagation type.

marker position over 30 frames prior to the start of the test. The mean uncertainty is reported and was less than $1 \mathrm{~mm}$ for all tests. We found this uncertainty low enough for the purposes of this study, but it is larger than in previous studies (van Herwijnen et al., 2010; Bair et al., 2012) since uncertainty increases with beam length.

\section{Field results}

\subsection{All tests}

The proportion of ECTs that propagated fully decreased as $l$ increased: 44,35 , and $27 \%$ for $1-2,2-5$ and $\geq 5 \mathrm{~m}$ ECTs. The proportion of PSTs that propagated fully decreased similarly: 53,30 , and $15 \%$ for $1-2,2-5$, and $\geq 5 \mathrm{~m}$ PSTs (Table 1, Fig. 3). This decrease is remarkable given that the longer tests were only attempted on days with full propagation in the standard tests. The longest tests that fully propagated were $7 \mathrm{~m}$. We tried a few $10 \mathrm{~m}$ tests, but none had full propagation. All of the $\geq 5 \mathrm{~m}$ tests failed on thick layers (6$14 \mathrm{~cm}$ ) of fist hardness depth hoar or facets. We tried some 2-4 m beams on weak layers composed of precipitation particles, but all had no propagation. Tests with partial or no propagation did not show consistent trends with $l$.

The CPSTs showed similar percentages for full propagation (54\%) compared to the standard PSTs. The most interesting finding about the CPSTs is that, as predicted by the anticrack model, they had almost exactly double the critical cut

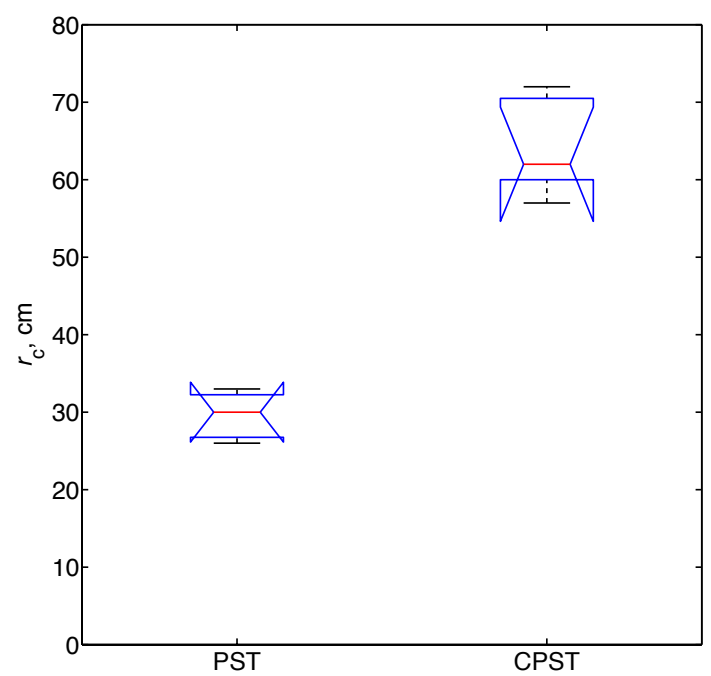

Figure 4. Critical cut lengths $\left(r_{\mathrm{c}}\right)$ for edge (PST) and CPSTs. All tests fully propagated and were done side by side (19/12/2012; Table 1). Median values are red lines, boxes are $25 \mathrm{th} / 75$ th percentiles, and whiskers are ranges. Nonoverlapping notches show significantly different groups at the $5 \%$ level from the Kruskal-Wallis test $(p=0.009) . N=5$ PSTs and 5 CPSTs.

length $r_{\mathrm{c}}$ of the PST (Fig. 4). The median $r_{\mathrm{c}}$ was $0.30 \mathrm{~m}$ for PSTs, $0.62 \mathrm{~m}$ for CPSTs, and the groups were significantly different (Kruskal-Wallis $p=0.009$ ).

\subsection{Particle tracking on selected tests}

For particle tracking analysis, we selected results from all of the longer ( $\geq 5 \mathrm{~m}$ ) tests that propagated fully but did not slide downhill (Table 2). We therefore excluded two tests (a $6 \mathrm{~m} \mathrm{ECT} \mathrm{on} \mathrm{13/03} \mathrm{and} \mathrm{a} 6 \mathrm{~m}$ PST on 14/03, Table 1) which fully propagated but then slid downhill. In tests that slide downhill, the collapse phase cannot be distinguished from the continuous bed surface erosion process (van Herwijnen and Jamieson, 2005). We also selected particle tracking results from $3 \mathrm{~m}$ tests that were done side by side to the longer tests for comparison. We would have liked to include particle tracking results from the $1.0-2.0 \mathrm{~m}$ tests done side by side to the longer tests but, on days with full propagation in the longer tests, the $1.0-2.0 \mathrm{~m}$ tests were not recorded on video because of time constraints in the field.

\subsubsection{Collapse amplitude}

The selected tests had similar collapse amplitudes $a$ (3$9 \mathrm{~mm}$ ) to those in other studies of failures on persistent weak layers (van Herwijnen and Jamieson, 2005; van Herwijnen et al., 2010; van Herwijnen and Birkeland, 2014). Plotting horizontal position against collapse amplitude shows that a steady state was not reached, even after almost $7 \mathrm{~m}$ (Fig. 5a, b). This result supports a previous study that also found no steady state in shorter tests (van Herwijnen et al., 2010). 
Table 1. Summary of propagation test results. Tests listed by location, date, and propagation code: 0 is no propagation, 1 is partial propagation, 2 is full propagation. Selected tests (Table 2) are marked with an asterisk.

\begin{tabular}{|c|c|c|c|c|c|c|c|c|}
\hline Date & Location & ECT, $1-2 \mathrm{~m}$ & ECT, 2-5 m & $\mathrm{ECT}, \geq 5 \mathrm{~m}$ & PST, $1-2 \mathrm{~m}$ & PST, $2-5 \mathrm{~m}$ & $\mathrm{PST}, \geq 5 \mathrm{~m}$ & CPST \\
\hline 29-11-2011 & CA & 0,0 & & & 0,0 & & & \\
\hline 01-03-2012 & CA & 0 & & & & & & \\
\hline $17-03-2012$ & CA & 0 & & & 0 & & & \\
\hline $13-04-2012$ & CA & 0 & & & 1 & 0 & & 1,0 \\
\hline $20-11-2012$ & CA & 0 & & & 2 & 0 & & 0,0 \\
\hline $23-11-2012$ & CA & & & & 0,0 & & & 0 \\
\hline $27-11-2012$ & $\mathrm{CA}$ & & & & $0,2,2$ & 1,1 & & \\
\hline $14-12-2012$ & CA & 0 & & & & & & \\
\hline $18-12-2012$ & CA & 0,0 & & & $0,0,0,2$ & & & 0,2 \\
\hline $19-12-2012$ & CA & & & & $2,2,2,2,2$ & & & $2,2,2,2,2$ \\
\hline $20-12-2012$ & $\mathrm{CA}$ & & & & $1,1,2$ & 1,2 & & \\
\hline $21-12-2012$ & $\mathrm{CA}$ & 0 & & & 2 & & & 2 \\
\hline $26-12-2012$ & $\mathrm{CA}$ & 2 & 1 & & & & & \\
\hline 02-01-2013 & $\mathrm{CA}$ & 2,0 & $2 *$ & $2 *$ & & & & \\
\hline 03-01-2013 & CA & 2 & & $2 *$ & 2,2 & & & \\
\hline 04-01-2013 & CA & 0,0 & & 0 & & & & \\
\hline 08-01-2013 & CA & 2 & 0 & & & 2 & 0 & \\
\hline 09-01-2013 & CA & 2 & $2 *$ & $2^{*}, 2^{*}$ & & & & \\
\hline 09-01-2013 & MT & $0,0,2$ & & & & & & \\
\hline $11-01-2013$ & CA & & $2 *$ & $1,2^{*}$ & & & & \\
\hline $14-01-2013$ & $\mathrm{CA}$ & & & $0,0,0$ & & & & \\
\hline $16-01-2013$ & MT & 2 & $0,2,2$ & $0,0,0,0,1,1$ & & & & \\
\hline $18-01-2013$ & $\mathrm{CA}$ & 0 & & & & & 0 & \\
\hline $22-01-2013$ & CA & 2 & 0,0 & & & 0 & & \\
\hline $23-01-2013$ & CA & $2,0,0,2$ & & 0 & $2,0,2$ & & 0 & \\
\hline 28-01-2013 & CA & 2 & & & & & & \\
\hline $29-01-2013$ & $\mathrm{CA}$ & 0,0 & & & 0,0 & & & \\
\hline $31-01-2013$ & CA & 0 & & & & & & \\
\hline $18-02-2013$ & UT & 2 & 1,0 & & & 2,0 & 0,0 & \\
\hline $19-02-2013$ & MT & 2 & & 0 & & & 0 & \\
\hline $20-02-2013$ & MT & 2,2 & & 0 & 2 & & $1,2 *$ & \\
\hline 21-02-2013 & MT & $0,0,2$ & & & & & 0 & \\
\hline $22-02-2013$ & MT & 2 & 2 & 1 & & & & \\
\hline $11-03-2013$ & CA & $0,0,2$ & 0 & & $0,0,2$ & & 0 & \\
\hline $12-03-2013$ & CA & 1,2 & 0 & 0 & 2,2 & & 1 & \\
\hline $13-03-2013$ & $\mathrm{CA}$ & 2 & & 2 & & & & \\
\hline $14-03-2013$ & $\mathrm{CA}$ & & & & & & 2,1 & \\
\hline 28-03-2013 & CA & $0,0,0,2,2,2$ & 0,0 & & & & & \\
\hline
\end{tabular}

Table 2. Selected tests with full propagation. For an explanation of why these tests were selected see Section 3.2. Location a - Rock Creek Canyon, CA; b - Yellow Mountain, MT; fps - frames per second; $\theta$ - slope angle; test beam length $l$; Test and score - see Greene et al. (Chapter 2, 2010); $\varepsilon$ - displacement uncertainty; $\lambda$ - wavelength; $c$ - mean wave speed; $a$ - mean collapse amplitude; $\rho$ - mean slab density; $h$ - mean slab height; FL - failure layer crystal type and size (Fierz et al., 2009).

\begin{tabular}{|c|c|c|c|c|c|c|c|c|c|c|c|c|c|c|}
\hline Number & Date & Location & fps & $\theta,^{\circ}$ & $l, \mathrm{~m}$ & Test and score & $\varepsilon, \mathrm{mm}$ & $\lambda, \mathrm{m}( \pm 0.5 \mathrm{~m})$ & $c, \mathrm{~ms}^{-1}$ & $\mathrm{a}, \mathrm{mm}$ & $\rho, \mathrm{kg} \mathrm{m}^{-3}$ & $h, \mathrm{~cm}$ & FL & FL size, $\mathrm{mm}$ \\
\hline 1 & 02-01-2013 & a & 240 & 2 & 3 & ЕСТP 22 & 0.3 & NA & 28 & 9.2 & 216 & 58 & $\mathrm{f}$ & $2-4$ \\
\hline 2 & 02-01-2013 & a & 240 & 2 & 5 & ЕСТР 23 & 0.4 & 3.0 & 35 & 5.4 & 216 & 58 & $\mathrm{f}$ & $2-4$ \\
\hline 3 & 03-01-2013 & $\mathrm{a}$ & 240 & 1 & 7 & ЕСТP 26 & 0.9 & 3.0 & 24 & 5.6 & 216 & 55 & $\mathrm{f}$ & $2-4$ \\
\hline 4 & 09-01-2013 & a & 240 & 0 & 3 & ЕCTP 24 & 0.2 & NA & 20 & 7.1 & 249 & 45 & $\mathrm{f}$ & $2-3$ \\
\hline 5 & 09-01-2013 & a & 240 & 0 & 5 & ЕСТР 24 & 0.2 & 2.5 & 19 & 3.8 & 249 & 45 & $\mathrm{f}$ & $2-3$ \\
\hline 6 & 09-01-2013 & $\mathrm{a}$ & 240 & 0 & 7 & ЕСТР 24 & 0.5 & 3.0 & 15 & 3.9 & 249 & 45 & $\mathrm{f}$ & $2-4$ \\
\hline 7 & 11-01-2013 & $\mathrm{a}$ & 30 & 0 & 3 & ЕСТР 25 & $<0.1$ & NA & 14 & 2.9 & 249 & 52 & $\mathrm{f}$ & $2-4$ \\
\hline 8 & 11-01-2013 & $\mathrm{a}$ & 30 & 0 & 7 & ECTP 25 & $<0.1$ & 3.0 & 21 & 3.3 & 249 & 52 & $\mathrm{f}$ & $2-4$ \\
\hline 9 & $20-02-2013$ & $\mathrm{~b}$ & 30 & 28 & 6 & PST End 25/600 & 0.2 & 3.0 & 16 & 5.6 & 197 & 50 & $\mathrm{e}$ & 2 \\
\hline
\end{tabular}



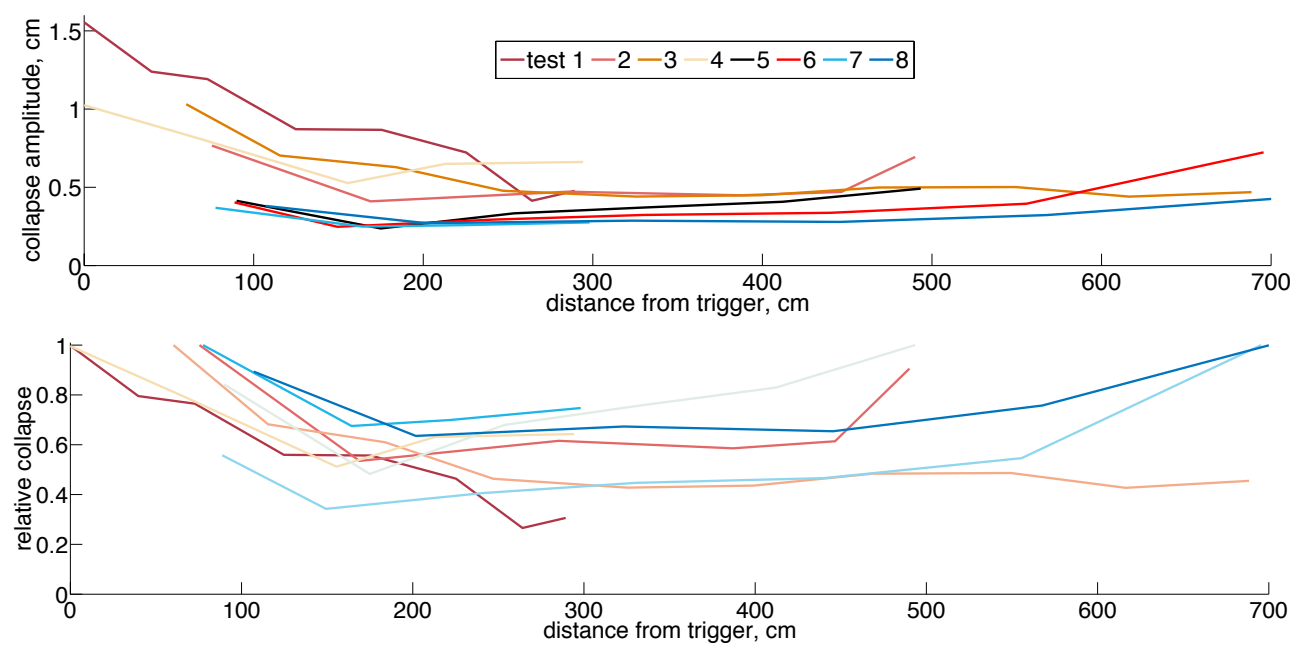

Figure 5. (a) Collapse vs. distance from trigger for tests 1-8. Collapse values are total displacements after movement has stopped. Absolute collapse values shown in (a), collapse values normalized by the maximum collapse in each test shown in (b).

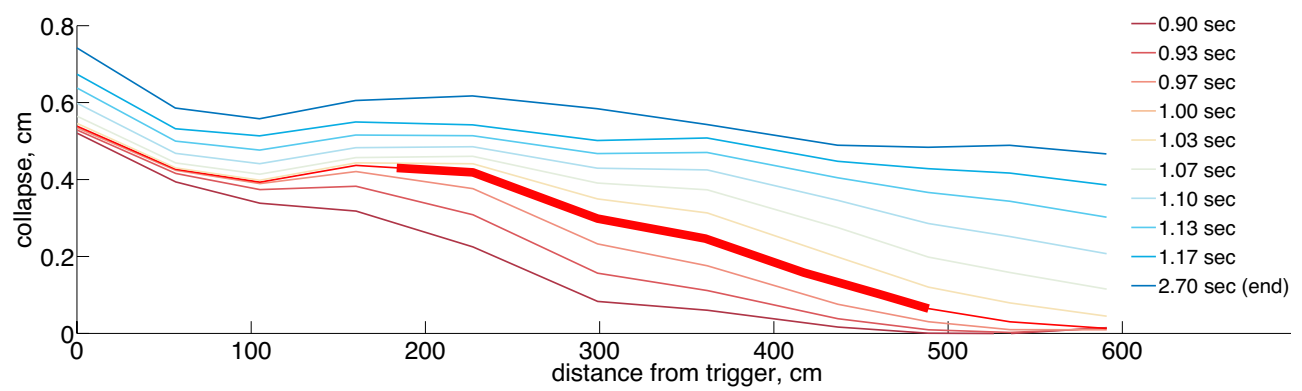

Figure 6. Wavelength of a PST. Collapse values shown during failure. The final value at $2.7 \mathrm{~s}$ is the total collapse after the beam stopped moving. The thick red line shows an estimate of the section of the beam undergoing rapid collapse (phase ii in Sect. 2.3), from which wavelength was estimated. The wavelength is $\sim 3 \mathrm{~m}$. Test 9 shown.

In the selected tests, greater collapse occurred near one or both of the beam edges than in the center of the beam (Fig. 5b). Relative to the center of the beam, markers near the trigger edge collapsed $160 \%$ and markers near the far end collapsed $128 \%$, on average. Markers near the trigger end of the beam collapsed more than the center in every test. Markers near the far end of the beam collapsed more than the center in seven of nine tests.

\subsubsection{Wavelength}

The wavelengths (2.5-3.3 m; e.g., Fig. 6) are much longer than what is predicted by the anticrack model. The model predicts wavelengths of $1.4-1.6 \mathrm{~m}$ for the slabs and weak layers in this study (Eq. (5.17) in Heierli, 2008). Our wavelengths are about two times larger than the only experimentally measured wavelength of $1.6 \mathrm{~m}$ (Heierli, 2008).

\subsubsection{Wave speed}

Collapse wave speeds ranged from 14 to $35 \mathrm{~m} \mathrm{~s}^{-1}$ and are consistent with previous studies (van Herwijnen and Jamieson, 2005; van Herwijnen et al., 2010; van Herwijnen and Schweizer, 2011; van Herwijnen and Birkeland, 2014). We found no dependence between wave speed and slab density, height, or collapse amplitude.

\subsubsection{Collapse amplitude with time}

Because tests 1-8 were all done in the same place and on the same failure layer, we were able to track the collapse amplitude over 11-12 days, until the tests had no propagation (Fig. 7). The average decrease in collapse amplitude was $-0.65 \mathrm{~mm} \mathrm{day}^{-1}$, with the $3 \mathrm{~m}$ beams showing the largest decrease. Similarly, the ECT scores for these tests generally increased with time (Table 2). There was no perceptible change in weak layer thickness; it stayed at $6 \mathrm{~cm}$ thick over this time period. 


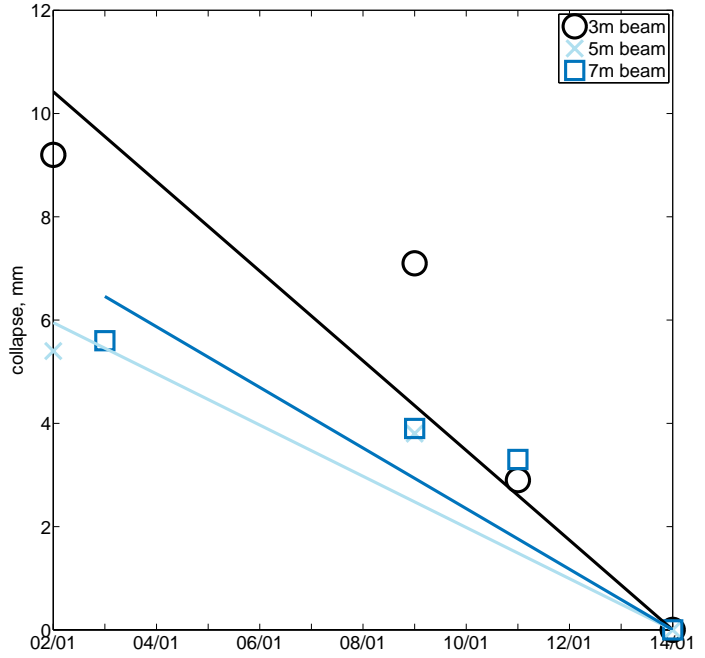

Figure 7. Decreasing collapse amplitudes with time. Collapse amplitudes were averaged across each beam. Tests 1-8 shown. Regression lines were forced through 13/01 and 14/01, when all tests had no propagation (collapse amplitude $0 \mathrm{~mm}$ ). The average slope coefficient is $-0.65 \mathrm{~mm}$ day $^{-1}$.

\section{Finite element (FE) modeling}

We modeled profiles from the field tests using finite element analysis in ANSYS 14.0. Specifically, the FE method allowed us to explore how changing the test length $l$ affected the strain energy of the slab $U$. Because it is simpler to model bending during a PST than the more dynamic ECT, we choose to model PSTs. Our edge effect analysis hinges on measuring the crack length prior to propagation, which is not possible with the ECT. We assume that the far edge effect is similar enough for both tests that general results from the FE analysis using a PST can also be applied to the ECT.

We used an FE model developed specifically for PSTs (Sigrist, 2006). The critical energy release rate $G_{\mathrm{c}}$ was estimated in a two-step process where the sum of strain energy $U$ (ANSYS command SENE) was estimated for $U\left(r_{\mathrm{c}}-\partial r\right)$ and $U\left(r_{\mathrm{c}}\right)$ :

$G_{\mathrm{c}} \approx-\frac{1}{b} \frac{U\left(r_{\mathrm{c}}\right)-U\left(r_{\mathrm{c}}-\partial r\right)}{\partial r}$,

where $\partial r=0.002 \mathrm{~m}$. This modeled situation represents the change in strain energy from a slightly shorter crack length than the critical length to the critical length. Thus, we approximate the critical energy release rate:

$G_{\mathrm{c}}=-\frac{1}{b} \frac{\partial U\left(r_{\mathrm{c}}\right)}{\partial r}$.

We modeled three different snow profiles observed in the field. These profiles were from 03/01/2013, 13/04/2012, and 11/03/2013 (Fig. 8a, b, c; Table 1). For one day, tests of up to $l=7 \mathrm{~m}$ had full propagation (Fig. $8 \mathrm{a}$ ). For the other two days, tests with $l=1.4-1.5 \mathrm{~m}$ had full propagation, but tests
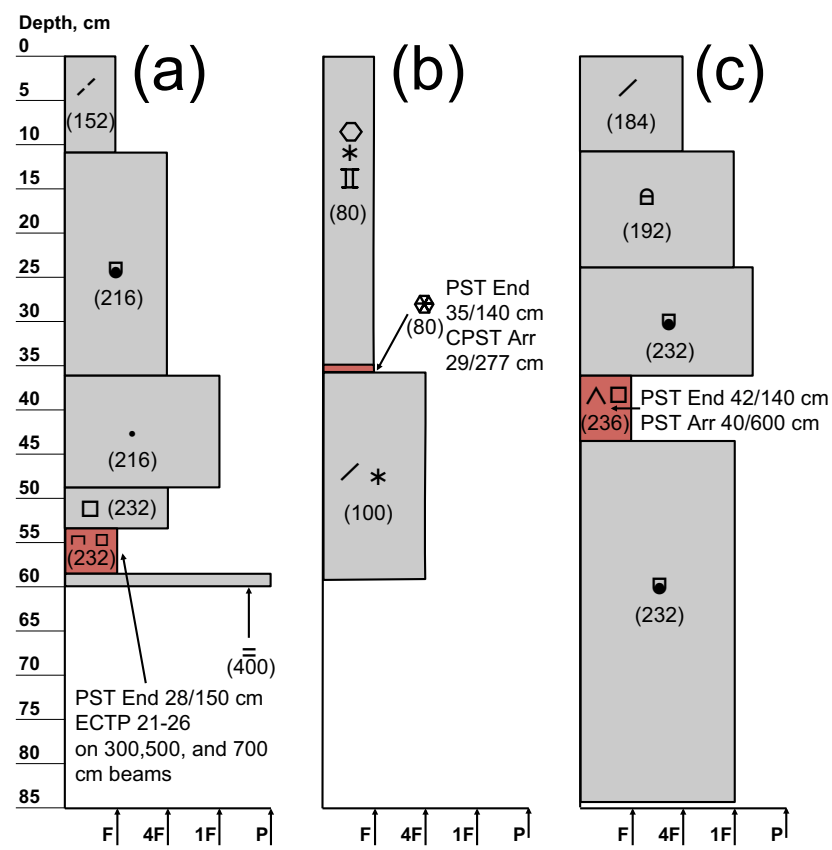

Figure 8. (a-c) Profiles for FE simulation. Profiles for each of the finite element simulations. Depth is from the snow surface, hand hardness is on the horizontal axis, and layer densities $\left(\mathrm{kg} \mathrm{m}^{-3}\right)$ are in parenthesis. The weak layer is red. The symbols for snow crystal types are from the "International Classification for Seasonal Snow on the Ground" (Fierz et al., 2009).

with $l \geq 2 \mathrm{~m}$ had no propagation (Fig. $8 \mathrm{~b}, \mathrm{c}$ ). The profiles had 3-6 layers: a fixed substrate, weak layer, and 1-4 layers in the slab. Each layer was modeled as an isotropic linear elastic material with Poisson's ratio $v=0.17$ and an elastic modulus $E$ estimated from the measured density $\rho$ (Scapozza, 2004):

$E=0.2 \mathrm{MPa} \exp \left[\frac{\rho}{67 \mathrm{~kg} \mathrm{~m}^{-3}}\right]$.

Our linear elastic assumption is addressed and compared with a viscoelastic model in Appendix A. The SOLID187 element type was used. This is a 10 node element with quadratic displacement behavior and three degrees of freedom. The mesh element line size was $5 \mathrm{~cm}$, with a finer resolution mesh applied at the crack tip and weak layer (ANSYS command SMRTSIZE). The edge notch in the PST was modeled as a $0.002 \mathrm{~m}$ thick gap in the center of the weak layer. We choose the center of the weak layer for the notch because this was how we notched our field tests. The weak layers were $0.01-0.07 \mathrm{~m}$ thick. These weak layers are thicker than those in other FE models of PSTs, where the weak layers and the edge notches were the same thickness, either $0.002 \mathrm{~m}$ (Sigrist, 2006) or $0.003 \mathrm{~m}$ (Schweizer et al., 2011). In all of the FE tests, tangency or crack-face contact did not occur, as maximum slope normal displacement was around $0.001 \mathrm{~m}$. As with the field tests, the FE beams were all $0.30 \mathrm{~m}$ wide. 


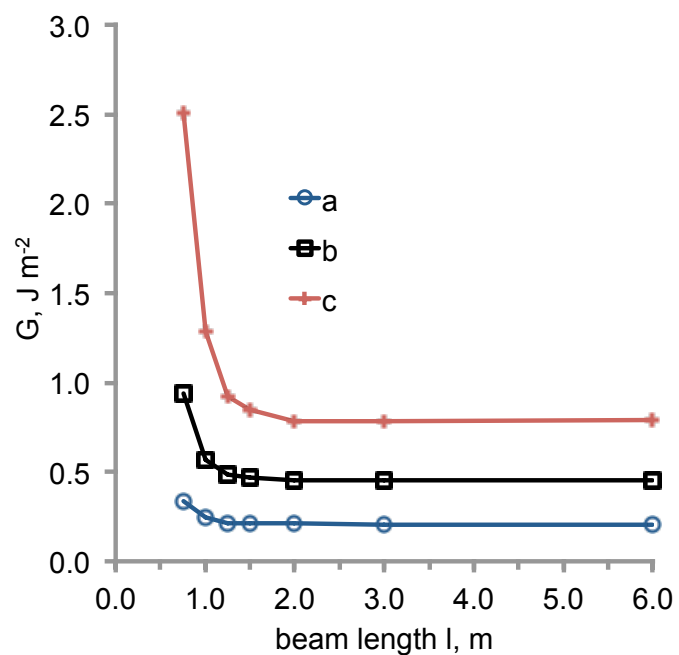

Figure 9. Energy release rate $G$ vs. beam length $l$. $G$ is plotted for test lengths $l=0.75-6.00 \mathrm{~m}$ for each of the profiles $(\mathbf{a}, \mathbf{b}, \mathbf{c})$ in Fig. 8. For each profile, the crack length is $r_{\mathrm{c}}$, the measured critical length from 1.4-1.5 m long field tests (Sect. 2.1).

\subsection{FE correction factor}

To compensate for the far edge effect in our FE tests, we introduce a geometrical correction factor $F(r / l)$ to relate $G$ to its asymptotic value $G_{\infty}$ :

$G_{\infty}=F(r / l) G$,

where $l$ is the sample length, $r$ is the crack length, and $r / l$ is the relative crack length. We calculate the correction factor as

$F(r / l)=\frac{\min [G(r, l)]}{G(r, l)}$,

where $\min [G(r, l)]$ is the minimum value of $\mathrm{G}$ for $l=0.75$ $6.00 \mathrm{~m}$. We chose $r=r_{\mathrm{c}}$, where $r_{\mathrm{c}}$ is the critical cut length from a field PST with $l=1.40-1.50 \mathrm{~m}$. We expect $F(r / l)$ to increase with $r / l$ because of the increased stress concentration from the far, free edge. Our goal is to find the maximum value of $r / l$ where $G_{\infty} \approx G$, i.e., $F(r / l) \approx 1$. The value will give us the test geometry that minimizes the effect from the far edge.

\subsection{FE simulations}

The FE simulations show that $G$ decreases with $l$ (Fig. 9). The function $G$ becomes asymptotic at $l \approx 2 \mathrm{~m}$, suggesting the far edge effect becomes negligible after $2 \mathrm{~m}$. Using Eq. (5), we computed $F(r / l)$ and plotted the results (Fig. 10). The curves from each profile (Fig. 8a, b, c) are almost identical, suggesting that $F(r / l)$ can be applied to persistent and nonpersistent weak layers. For all the profiles, the asymptote is at $r / l \approx 0.20$. This asymptote suggests that the far edge effect becomes significant for $r / l>0.20$. In terms

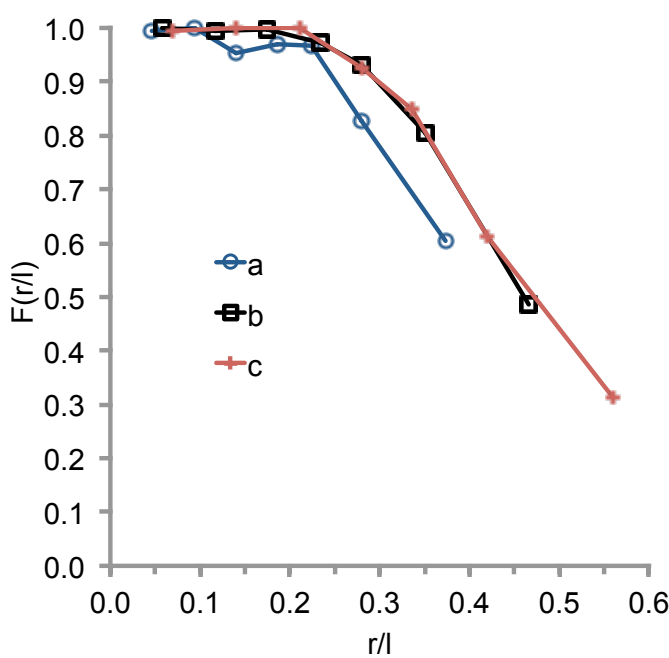

Figure 10. Correction factor $F(r / l)$ vs. relative cut length $r / l$. Correction factor $F(r / l)$ from Eq. (5) for three profiles from Fig. 8.

of a $1 \mathrm{~m}$ PST, cut lengths $>20 \mathrm{~cm}$ will be subjected to increased stress from the far edge.

\section{Discussion}

The finding that full propagation decreased with test length is central to this study. We find that cracks in shorter tests are more prone to influence from the far edge than in longer tests, and this edge effect causes them to fully propagate more often. Our FE simulations show that, in shorter tests, $G$ is higher than its asymptotic value $G_{\infty}$. The crack propagation criterion $G \geq G_{\mathrm{c}}$, where $G_{\mathrm{c}}$ is the critical energy release rate, may be met for crack lengths in shorter tests that are subcritical in longer tests. This suggests that shorter tests could fully propagate when slope scale failure is unlikely.

Estimated collapse wavelengths were double or longer than what is predicted by the anticrack model. There are three explanations: (1) measurement uncertainty, (2) incorrect assumptions in the model, and/or (3) the elastic modulus values used in the model are too low. Measurement uncertainty may be caused by including markers undergoing bending and bed surface erosion in addition to the rapid collapse phase. Using our measurement uncertainty of $\pm 0.5 \mathrm{~m}$, a conservative estimate of the modal wavelength $(3 \mathrm{~m})$ for our tests is still $2.5 \mathrm{~m}$, about $1 \mathrm{~m}$ greater than what is predicted by the anticrack model. For the anticrack model to give wavelengths of $3 \mathrm{~m}$ for these slabs, the elastic modulus would have to be around $100 \mathrm{MPa}$, one or two orders of magnitude greater than values recorded in experimental results for slabs with the densities in this study (Scapozza, 2004; Sigrist and Schweizer, 2007; Schweizer et al., 2011). It is more likely that the model has some incorrect assumptions. In particular, we suggest the free fall assumption of the anticrack model is incorrect. Residual support between the 
slab and weak layer could mean the slab is never in free fall. This support could explain the longer wavelengths. A good method to test if a slab is in free fall is to study the instantaneous acceleration values. Unfortunately, our video cameras did not sample fast enough to measure instantaneous acceleration with any certainty.

We experimented with CPSTs, and found that, as predicted by the anticrack theory, $r_{\mathrm{c}}$ doubled. Our results suggest that a beam with length double that of a PST would be needed to minimize edge effects in a CPST. CPSTs are also harder to perform, as the operator must keep track of where the saw was inserted into the beam. From a practical perspective, we suggest that a PST provides as much information to the user as a CPST and only requires a beam half as long to be excavated.

The observed decrease in collapse amplitude is not directly related to edge effects, but interesting nonetheless. To our knowledge, this is the first study to track the evolution of collapse amplitude over time. The $0.65 \mathrm{~mm} \mathrm{day}^{-1}$ average decrease in collapse amplitude is evidence of a strengthening weak layer. The concurrent increase in ECT scores supports the idea that the weak layer was gaining strength during this time period. It's also likely that the slab lost strength, which made it less able to transmit the propagating collapse wave without fracturing itself. The snowpack remained shallow (around $70 \mathrm{~cm}$ ) and temperatures cooled, with the average daily air temperature dropping to $-20.0^{\circ} \mathrm{C}$ on $12 / 01$ and $13 / 01$. These conditions set up a strong temperature gradient. Crystal forms in the slab changed from new snow and faceting rounds to an almost entirely faceted slab.

The FE simulations allowed us to change $l$, while keeping all other parameters fixed for a given profile. The asymptote at $r / l \approx 0.20$ suggests relative crack lengths longer than $20 \%$ are subject to influences from the far edge of the beam. This finding contrasts with PST guidelines, which recommend a test length of $1 \mathrm{~m}$ and suggest $r_{\mathrm{c}} / l \leq 0.50$ accompanied by "End" propagation indicates likely crack propagation (Gauthier and Jamieson, 2008).

The FE results suggest that the far edge effect becomes negligible for PSTs $\geq 2 \mathrm{~m}$. Thus, the FE results explain the decrease in full propagation between the 1-2 and 3-5 m PSTs. The FE results cannot explain the continued decrease in full propagation for the $\geq 5 \mathrm{~m}$ PSTs. One possibility is that increasing spatial variability in the slab and weak layer caused the continued decrease in full propagation. The coefficient of variation (CV) for the collapse amplitudes in tests 18 , one measure of spatial variability, showed no relationship with test length $l$ for side-by-side tests. If spatial variability increased with test length, one might expect this CV to increase with $l$. Still, we cannot rule out the effect of spatial variability on crack propagation. To fully assess the effect of spatial variability on crack propagation would require measurements on properties such as penetration resistance across the test beams and weak layers.
The ECT was not modeled with the FE model. Given that ECTs showed concurrent decreases in full propagation with test length along with PSTs, it is likely that $G$ in an ECT also decreases with $l$, holding all else constant. In fact, given the dynamic nature of the ECT, reflected stress waves (Anderson, 2005), another edge effect, may be significant in an ECT as well. Reflected stress waves can combine constructively and destructively with stress fields at the crack tip resulting in complex interactions, but they could significantly increase $G$.

Based on our results, we suggest that ECT and PST length guidelines be revisited. Our results imply that $2 \mathrm{~m}$ ECTs and PSTs could reduce false unstable rates compared to standard length tests. Alternatively, $2 \mathrm{~m}$ tests could increase the false stable rate, which is arguably the most important metric for a stability test. High false stable rates mean that stable test results are associated with unstable slopes, which is potentially dangerous. We propose testing standard length and $2 \mathrm{~m}$ ECTs and PSTs side by side on stable and unstable slopes to compare accuracy.

\section{Conclusions}

We performed 163 propagation tests spanning an order of magnitude in length. The proportion of tests that propagated fully decreased as test length increased. The shorter tests likely propagated fully more often because of stress intensification from the far edge. Evidence of this far edge effect was that collapse amplitudes were greater at beam ends than in the centers. Our finding that full propagation decreased with test length was corroborated with FE simulations. The simulations showed that the strain energy release rate $G$ decreased with test length $l$ for a given crack length $r$, before reaching an asymptotic value. The asymptote was at $r / l \approx 0.20$ or at $l \approx 2 \mathrm{~m}$ for typical critical crack lengths. For tests $\geq 2 \mathrm{~m}$, we speculate that spatial variability could explain the continued decrease in full propagation.

We confirmed the prediction from the anticrack model that CPSTs would have $r_{\mathrm{c}}$ values double that of PSTs. Given the extra work of CPSTs, we find them impractical for reducing edge effects compared to longer PSTs.

A time-series of unstable ECTs over 11-12 days performed at the same location allowed us to track collapse amplitude over time. On average, collapse amplitude decreased $0.65 \mathrm{~mm} \mathrm{day}^{-1}$ as the weak layer gained strength. This decrease coincided with an increase in ECT scores. To our knowledge, this study is the first to report trends in collapse amplitude over time.

We suggest that ECT and PST length guidelines be revisited. Our results show that $2 \mathrm{~m}$ tests could decrease false unstable results compared to standard length tests. We propose side-by-side tests on stable and unstable slopes to determine if $2 \mathrm{~m}$ tests are more (or less) accurate than standard length tests. 


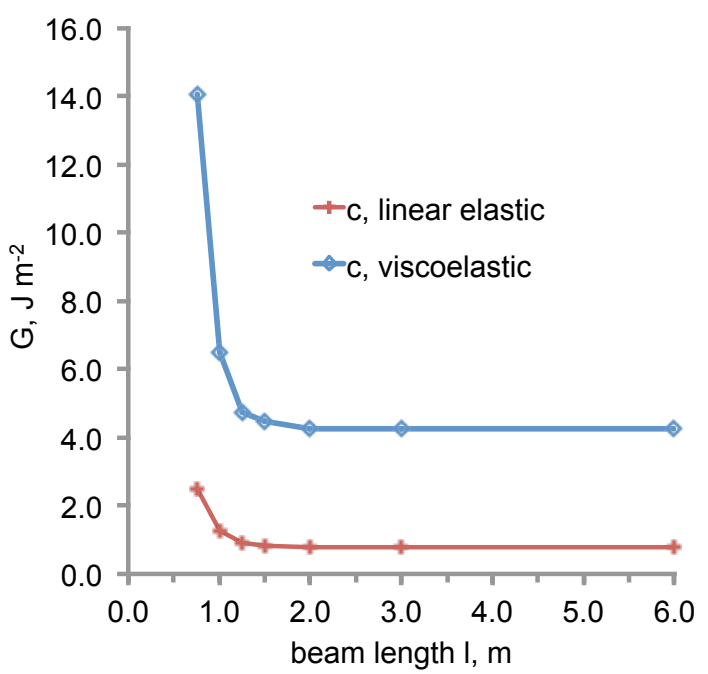

Figure A1. Energy release rate $G$ vs. beam length $l$ for two versions of the FE model run on profile $c$. The curve " $c$, linear elastic" shows results from a model assuming linear elastic behavior, while the curve " $c$, viscoelastic" shows results from a model incorporating viscoelastic effects.

\section{Appendix A: Viscoelastic effects}

Because of our linear elasticity assumption, we used a fixed value for $E$ for each layer. In reality, snow has been shown to exhibit strain softening (McClung, 1977), where $E$ decreases with increasing strain because of microcracking and other mechanisms. Our hypothesis was that the linear elasticity assumption has little impact on our results; nonetheless we tested a version of our model with strain softening using a mixture model where the slab and weak layer are treated as one layer with an effective modulus $E^{\prime}$ that takes into account viscoelastic effects (McClung, 2011; McClung and Borstad, 2012):
$E^{\prime}=2.22 \times 10^{-6}\left[10^{5.58+0.00857(\rho-215)}\right], \mathrm{MPa}$

For profile $c$ (Fig. 2), the average slab density $\rho=$ $204 \mathrm{~kg} \mathrm{~m}^{-3}$ and $E^{\prime}=0.68 \mathrm{MPa}$. Using these parameters, $G$ was much higher for the viscoelastic version of the model. The range for the viscoelastic version of the model, using profile $c$, was $4.28-14.07 \mathrm{~J} \mathrm{~m}^{-2}$ compared to 0.79 $2.50 \mathrm{~J} \mathrm{~m}^{-2}$ for the linear elastic version (Fig. A1). The viscoelastic model's values for $G$ exceed published $G_{\mathrm{c}}$ values (McClung, 2007; Sigrist and Schweizer, 2007; Heierli et al., 2008; Schweizer et al., 2011) by one or two orders of magnitude, suggesting that $E$ ' from Eq. (A1) is too low. Ultimately, the method for determining the elastic modulus did not impact our results regarding $l$ values that minimize the far edge effect. The asymptotic value of $G$ still occurred around $l=$ $2 \mathrm{~m}$ for both versions of the model. Thus, while viscoelastic effects may be important for an accurate estimate for $G$ (i.e., Bažant et al., 2003; McClung, 2005; Sigrist et al., 2005; McClung and Schweizer, 2006), they did not affect where $G$ reached its asymptotic value. Comparison of both model results show that the far edge effect on $G$ was eliminated in beams with $l \geq 2 \mathrm{~m}$. 
Acknowledgements. We thank Joachim Heierli for help with application of the anticrack model. We thank Chris Borstad for his comments. We gratefully acknowledge Michela Adrian, Joe Magajna, and Sue Burak of the Eastern Sierra Avalanche Center for their help with field work. We thank Toby Weed and Drew Hardesty from the Utah Avalanche Center and Doug Chabot and Mark Staples from The Gallatin National Forest Avalanche Center for directing us to places with propagation. Lastly, we thank Howard Conway and Bill Glude for their reviews. The first author is supported by a US Army Corps of Engineers Cold Regions Research and Engineering fellowship administered by ORISE/ORAU. This work was also supported by NSF EAR-1015057.

Edited by: A. Klein

\section{References}

Anderson, T. L.: Fracture Mechanics: Fundamentals and Applications, Taylor and Francis, Boca Raton, FL, 610 pp., 2005.

Bair, E. H., Simenhois, R., Birkeland, K., and Dozier, J.: A field study on failure of storm snow slab avalanches, Cold Reg. Sci. Technol., 79-80, 20-28, doi:10.1016/j.coldregions.2012.02.007, 2012.

Bažant, Z. P., Zi, G., and McClung, D.: Size effect law and fracture mechanics of the triggering of dry snow slab avalanches, J. Geophys. Res., 108, 2119, doi:10.1029/2002JB001884, 2003.

Birkeland, K. W., and Chabot, D.: Changes in stability test usage by Snowpilot users, Proceedings of the 2012 International Snow Science Workshop, Anchorage, AK, USA, 2012.

Crocker, J. C., and Grier, D. G.: Methods of digital video microscopy for colloidal studies, J. Coll. Int. Sci., 179, 298-310, doi:10.1006/jcis.1996.0217, 1996.

Fierz, C., Armstrong, R. L., Durand, Y., Etchevers, P., Greene, E., McClung, D. M., Nishimura, K., Satyawali, P. K., and Sokratov, S.: The International Classification for Seasonal Snow on the Ground, IHP-VII Technical Documents in Hydrology No. 83, 90, 2009.

Gauthier, D. and Jamieson, B.: Evaluation of a prototype field test for fracture and failure propagation propensity in weak snowpack layers, Cold Reg. Sci. Technol., 51, 87-97, doi:10.1016/j.coldregions.2007.04.005, 2008.

Greene, E., Atkins, D., Birkeland, K. W., Elder, K., Landry, C., Lazar, B., McCammon, I., Moore, M., Sharaf, D., Sterbenz, C., Tremper, B., and Williams, K.: Snow, Weather, and Avalanches: Observational Guidelines for Avalanche Programs in the United States, 136, 39-56, 2010.

Heierli, J.: Anticrack model for slab avalanche release, Institut für Zuverlässigkeit von Bauteilen und Systemen, 113, 102 pp., 2008.

Heierli, J., Gumbsch, P., and Zaiser, M.: Anticrack nucleation as triggering mechanism for snow slab avalanches, Science, 321, 240-243, doi:10.1126/science.1153948, 2008.

Heierli, J., Birkeland, K. W., Simenhois, R., and Gumbsch, P.: Anticrack model for skier triggering of slab avalanches, Cold Reg. Sci. Technol., 65, 372-381, doi:10.1016/j.coldregions.2010.10.008, 2011.

Jamieson, J. B.: The compression test - after 25 years, The Avalanche Review, 18, 10-12, 1999.

MathWorks: MATLAB R2013b Documentation, The MathWorks, Natick, MA, 679 pp., 2013.
McClung, D. M.: Direct simple shear tests on snow and their relation to slab avalanche formation, J. Glaciol., 19, 101-109, 1977.

McClung, D. M.: Shear fracture precipitated by strain softening as a mechanism of dry slab avalanche release, J. Geophys. Res., 84, 3519-3526, doi:10.1029/JB084iB07p03519, 1979.

McClung, D. M.: Dry slab avalanche shear fracture properties from field measurements, J. Geophys. Res., 110, F04005, doi:10.1029/2005JF000291, 2005.

McClung, D. M.: Fracture energy applicable to dry snow slab avalanche release, Geophysical Research Letters, 34, L02503, doi:10.1029/2006g1028238, 2007.

McClung, D. M.: Dry snow slab quasi-brittle fracture initiation and verification from field tests, J. Geophys. Res., 114, F01022, doi:10.1029/2007JF000913, 2009.

McClung, D. M.: Analysis of critical length measurements for dry snow slab weak-layer shear fracture, J. Glaciol., 57, 557-566, doi:10.3189/002214311796905541, 2011.

McClung, D. M. and Borstad, C. P.: Deformation and energy of dry snow slabs prior to fracture propagation, Journal of Glaciolgy, 58, 553-564, doi:10.3189/2012JoG11J009, 2012.

McClung, D. M. and Schweizer, J.: Fracture toughness of dry snow slab avalanches from field measurements, J. Geophys. Res., 111, F04008, doi:10.1029/2005JF000403, 2006.

Newman, J. C. and Raju, I. S.: An empirical stress-intensity factor equation for the surface crack, Eng. Frac. Mech., 15, 185-192, doi:10.1016/0013-7944(81)90116-8, 1981.

Ross, C. K. H., and Jamieson, B.: The propagation saw test: slope scale validation and alternative test methods, J. Glaciol., 58, 407416, doi:10.3189/2012JoG11J192, 2012.

Scapozza, C.: Entwicklung eines dichte- und temperaturabhängigen Stoffgesetzes zur Beschreibung des visko-elastischen Verhaltens von Schnee, 251 pp., doi:10.3929/ethz-a-00468, 2004.

Schweizer, J., van Herwijnen, A., and Reuter, B.: Measurements of weak layer fracture energy, Cold Reg. Sci. Technol., 69, 139144, doi:10.1016/j.coldregions.2011.06.004, 2011.

Sigrist, C.: Measurement of fracture mechanical properties of snow and application to dry snow slab avalanche release, $139 \mathrm{pp}$., doi:10.3929/ethz-a-005282374, 2006.

Sigrist, C. and Schweizer, J.: Critical energy release rates of weak snowpack layers determined in field experiments, Geophysical Research Letters, 34, L03502, doi:10.1029/2006g1028576, 2007.

Sigrist, C., Schweizer, J., Schindler, H. J., and Dual, J.: On size and shape effects in snow fracture toughness measurements, Cold Reg. Sci. Technol., 43, 24-35, doi:10.1016/j.coldregions.2005.05.001, 2005.

Simenhois, R. and Birkeland, K.: The extended column test: a field test for fracture initiation and propagation, 2006 International Snow Science Workshop, 79-85, 2006.

Simenhois, R. and Birkeland, K.: The extended column test: test effectiveness, spatial variability, and comparison with the propagation saw test, Cold Reg. Sci. Technol., 59, 210-216, doi:10.1016/j.coldregions.2009.04.001, 2009.

van Herwijnen, A., and Heierli, J.: Measurement of crack-face friction in collapsed weak snow layers, Geophysical Research Letters, 36, L23502, doi:10.1029/2009g1040389, 2009.

van Herwijnen, A. and Jamieson, B.: High-speed photography of fractures in weak snowpack layers, Cold Reg. Sci. Technol., 43, 71-82, doi:10.1016/j.coldregions.2005.05.005, 2005. 
van Herwijnen, A. and Jamieson, B.: Fracture character in compression tests, Cold Reg. Sci. Technol., 47, 60-68, doi:10.1016/j.coldregions.2006.08.016, 2007.

van Herwijnen, A. and Schweizer, J.: Seismic sensor array for monitoring an avalanche start zone: design, deployment and preliminary results, J. Glaciol., 57, 267-276, 2011. van Herwijnen, A., Schweizer, J., and Heierli, J.: Measurement of the deformation field associated with fracture propagation in weak snowpack layers, J. Geophys. Res., 115, F03042, doi:10.1029/2009jf001515, 2010.

van Herwijnen, A. and Birkeland, K. W.: Using High-speed Video to Better Understand Extended Column Tests, Cold Reg. Sci. Technol., 97, 97-103, doi:10.1016/j.coldregions.2013.07.002, 2014. 